\title{
A Case of Elastography-Assisted Laparoscopic Fertility Preservation for Severe Deep Endometriosis Causing Ureteral Stenosis and Subtype II Adenomyosis
}

\author{
Yoshiaki Ota ${ }^{1}$, Kuniaki Ota ${ }^{2, *}$ (D) , Toshifumi Takahashi ${ }^{2}$ (D), Yumiko Morimoto ${ }^{1}$, So-Ichiro Suzuki ${ }^{1}$, Rikiya Sano ${ }^{1}$, \\ Ikuko Ota $^{3}$, Takuya Moriya ${ }^{4}(\mathbb{D})$ and Mitsuru Shiota ${ }^{1}$ \\ 1 Department of Gynecological Oncology, Kawasaki Medical School, Kurashiki 701-0192, Japan; \\ yoshimon@med.kawasaki-m.ac.jp (Y.O.); y_morimoto@med.kawasaki-m.ac.jp (Y.M.); \\ soichi731@gmail.com (S.-I.S.); sun102life@yahoo.co.jp (R.S.); mshiota@med.kawasaki-m.ac.jp (M.S.) \\ 2 Fukushima Medical Center for Children and Women, Fukushima Medical University, 1 Hikarigaoka, \\ Fukushima 960-1295, Japan; totakaha@fmu.ac.jp \\ 3 Department of Gynecology, Kurashiki Heisei Hospital, Kurashiki 710-0826, Japan; ikucom0195@gmail.com \\ 4 Department of Pathology, Kawasaki Medical School, Kurashiki 701-0192, Japan; \\ tmoriya@med.kawasaki-m.ac.jp \\ * Correspondence: kuniakiota@gmail.com; Tel.: +81-3-3762-4151
}

Citation: Ota, Y.; Ota, K.; Takahashi, T.; Morimoto, Y.; Suzuki, S.-I.; Sano, R.; Ota, I.; Moriya, T.; Shiota, M. A Case of Elastography-Assisted Laparoscopic Fertility Preservation for Severe Deep Endometriosis Causing Ureteral Stenosis and Subtype II Adenomyosis. Endocrines 2021, 2, 348-355. https://doi.org/ 10.3390/endocrines2030032

Academic Editors: Osamu Hiraike and Akira Iwase

Received: 23 May 2021

Accepted: 30 August 2021

Published: 9 September 2021

Publisher's Note: MDPI stays neutral with regard to jurisdictional claims in published maps and institutional affiliations.

Copyright: (c) 2021 by the authors. Licensee MDPI, Basel, Switzerland. This article is an open access article distributed under the terms and conditions of the Creative Commons Attribution (CC BY) license (https:/ / creativecommons.org/licenses/by/ $4.0 /)$.

\begin{abstract}
Adenomyosis is commonly treated by total hysterectomy. Adenomyomectomy is considered for women of reproductive age who wish to preserve their fertility. However, a high recurrence rate following adenomyomectomy has been reported because complete removal of the lesion is difficult, and uterine rupture during pregnancy remains a complication. We previously reported that laparoscopic adenomyomectomy using a cold knife prevented thermal damage to the myometrium and elastography to avoid residual lesions. Here, we report the case of a patient who underwent complete resection of a subtype II adenomyosis and resection of deep endometriosis (DE) with the closure of the pouch of Douglas. The patient was 31 years old, had severe dysmenorrhea, and had left ureteral stenosis and subtype II adenomyosis associated with the closure of the pouch of Douglas by the DE. After resection of the DE posterior wall adenomyosis, residual lesions were confirmed by laparoscopic real-time elastography. Eight weeks after surgery, postoperative transvaginal ultrasound showed that the myometrium had shrunk from 28 to $22.7 \mathrm{~mm}$, and the hydronephrosis had disappeared, although a stent remained necessary. In this study, we report the complete resection of subtype II adenomyosis and DE, combined with elastography to visualize the lesions during resection.
\end{abstract}

Keywords: adenomyosis; endometriosis; laparoscopic; elastography

\section{Introduction}

Clinically, there are three types of endometriosis: superficial peritoneal endometriosis, ovarian endometrioma (OMA), and deep endometriosis (DE) [1]. Another phenotype, adenomyosis, is characterized by the invasion of endometrial tissue into the myometrium, causing inflammation and hypertrophy [2,3]. Adenomyosis presents in different configurations, including diffuse, focal, and, rarely, cystic adenomyomas [4,5].

Various classification systems currently have been used to easily and uniformly describe the localization and severity of the lesions in women with endometriosis. The revised American Society for Reproductive Medicine (rASRM) score is the most widely used classification system [6]. In addition, the ENZIAN classification was developed [7] since it does not take into account the involvement of retroperitoneal structures with DE. However, it still appears to be more complicated than the rASRM score, although its use has been substantially simplified [8]. It is especially difficult for patients to understand the classification, and few research studies have been published in international journals 
regarding the classification [9]. Thus, Kishi et al. [10,11] simply described four subtypes of adenomyosis based on lesion location and their extension in the uterus as seen by magnetic resonance imaging: subtype I is confined to the inner uterine wall; subtype II is confined to the outer uterine wall; subtype III includes solitary lesions; and subtype IV includes all other lesions, and this classification is frequently used clinically owing to easier availability $[12,13]$.

Despite the existence of this clinically useful classification, total hysterectomy is frequently performed because the location and extent of the adenomyosis cannot be determined, making complete removal difficult, especially for subtypes 1 . Reproductive-aged women should be offered conservative surgeries when applicable and be informed that the excision of extensive adenomyosis is difficult and associated with a high recurrence rate [14-17]. We recently reported a case of subtype I adenomyosis treated using laparoscopic, conservative excision with intraoperative real-time elastography, with the adenomyosis lesion being completely resected [18]. Conversely, the proposed mechanism of DE, including subtype II, is that the lesion implants outside the uterus and infiltrates toward the inside of the myometrium $[10,11]$. Ultrasound frequencies, including elastography, are easier to delineate in shallow ranges than in deep ranges. Therefore, we hypothesized that intraoperative real-time elastography might be more useful in detecting subtype II adenomyosis, which would prevent postoperative residual adenomyosis by decreasing the difficulty in completely resecting these lesions. We present the case of a patient who underwent successful complete excision of subtype II adenomyosis with intraoperative real-type elastography. This study was reported following the surgical case report criteria [19].

\section{Case Presentation}

The patient was a 31-year-old woman, 0 parity, who complained of dysmenorrhea. A sagittal and an axial plane T2-weighted image revealed a 28-mm-thick subtype II adenomyosis with punctate high intensity (Figure 1a,b). Additionally, T2-weighted imaging revealed adhesion of the sigmoid colon to the posterior wall of the uterus, which was expected to be associated with complete closure of the pouch of Douglas. Fat-suppressed T1-weighted images revealed a 2.5-cm right OMA (Figure 1c). A transabdominal ultrasound exhibited left hydronephrosis, which was confirmed using contrast-enhanced computed tomography (CT) (Figure 1d). Adenomyosis subtype II with right OMA was the preoperative diagnosis (rASRM classification: 47 points, stage IV; ENZIAN classification: B3C1FAFU). As comorbidity, there was left ureteral stenosis due to entrapment of the left ureter in the DE. The patient was scheduled to undergo laparoscopic adenomyomectomy with real-time elastography, to detect residual adenomyotic tissue. After consulting the urological team, a double-J ureteral stent was inserted into the left ureter under cystoscopy to prevent intraoperative urinary injuries (Figure 1e). A gonadotropin-releasing hormone agonist (Buserelin acetate MP $1.8 \mathrm{mg}$; Aventis Pharma Ltd., Tokyo, Japan) was preoperatively used every four weeks, with a total of four times, to reduce the intraoperative bleeding. Laparoscopic surgery was performed under general anesthesia in the Trendelenburg position, with a four-port 2D/4K laparoscopy system (IMAGE1 S ${ }^{\mathrm{TM}} 4 \mathrm{U}$ Camera System; Karl Strorz, Tokyo, Japan). A 12-mm port (ENDOPATH XCEL ${ }^{\circledR}$; Ethicon Endo-Surgery, Cincinnati, $\mathrm{OH}, \mathrm{USA}$ ) was introduced intraumbilically for the zero-degree laparoscope, and three additional 5-mm lateral ports (ENDOPATH XCEL ${ }^{\circledR}$; Ethicon Endo-Surgery, Tokyo, Japan) were placed centrally and bilaterally under direct vision. The surgeon used the central and left-sided lateral ports to perform most surgical manipulations.

The pouch of Douglas completely adhered to the posterior wall of the uterus and rectum (Figure 2a). First, the lateral side of the rectum was dissected outside the mesorectum, and when the outline of the rectum was confirmed, the posterior wall of the uterus and rectum were dissected to open the pouch of Douglas. After the pouch of Douglas was opened, the DE near the sacrouterine ligament was identified. Entrapment of the left ureter on the left side of the DE was suspected to cause ureteral stenosis (Figure 2b). The left 
ureter was completely detached to its intersection with the uterine artery (Figure 2c). The DE was continuously removed with a monopolar needle electrode (Probe Plus II; Ethicon, Tokyo, Japan). Second, the center of the laparoscopic trocar was removed, and a \#11 scalpel was inserted into the abdominal cavity from the same site. The boundary between the adenomyosis and the normal myometrium was indistinct and could not be palpated with a power instrument, such as a harmonic scalpel. Therefore, we used a \#11 scalpel as in our previous study [18] since the adenomyosis and the normal myometrium can be easily distinguished with a scalpel. A longitudinal incision was made in the uterine serosa, and the adenomyosis lesion was nucleated (Figure 3a,b).

(a)

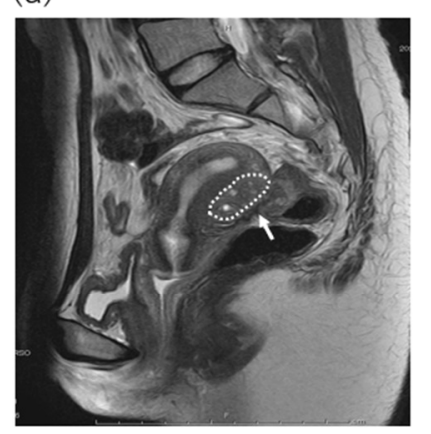

(d)

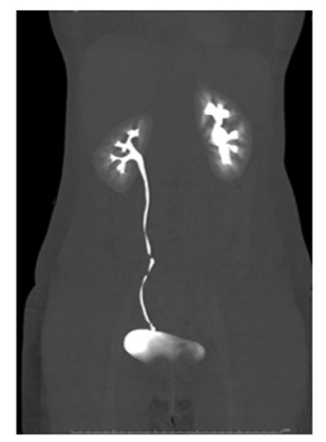

(b)

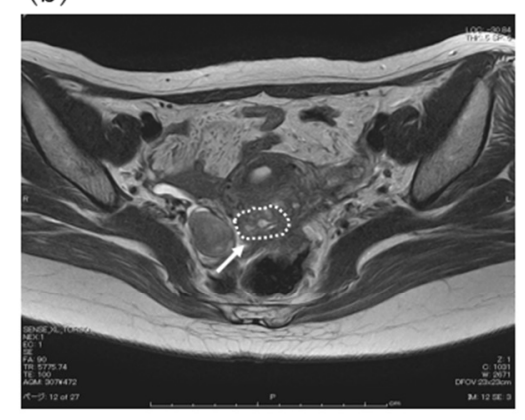

(e)

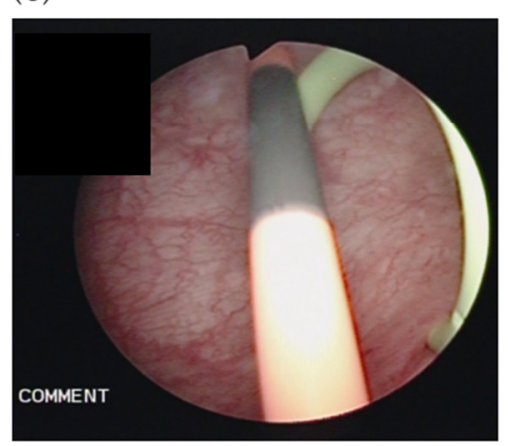

(c)

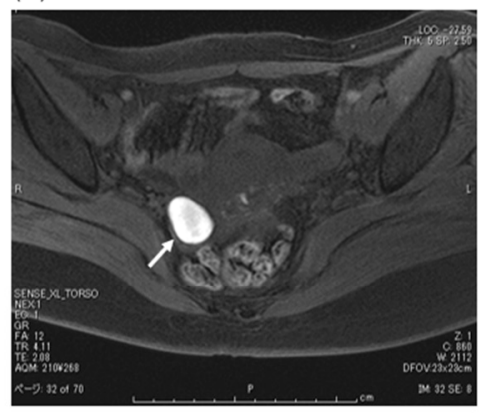

Figure 1. (a,b) T2-weighted image sagittal and axial sections showing extrinsic adenomyosis in the posterior wall of the uterus (white dotted circle), which was adherent to the sigmoid colon (white arrow). (c) T1-weighted image with fat suppression showing a high-intensity, 2-cm ovarian endometrioma (OMA) on the right (white arrow). (d) Contrast-enhanced computed tomography (CT) showing prominent left hydronephrosis. The left ureter also showed contrast delay. The left ureter was suspected to be compressed by the deep endometriosis (DE). (e) A left ureteral double-J stent was inserted using cystoscopy.

(a)

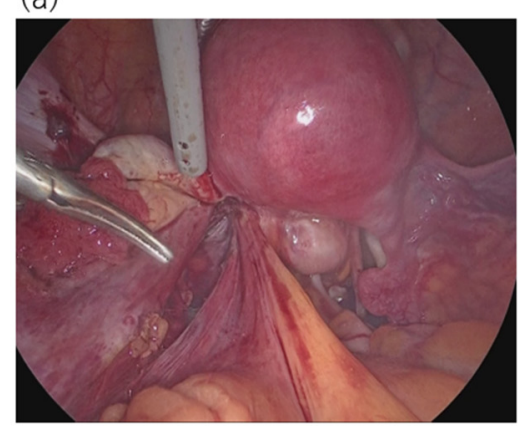

(b)

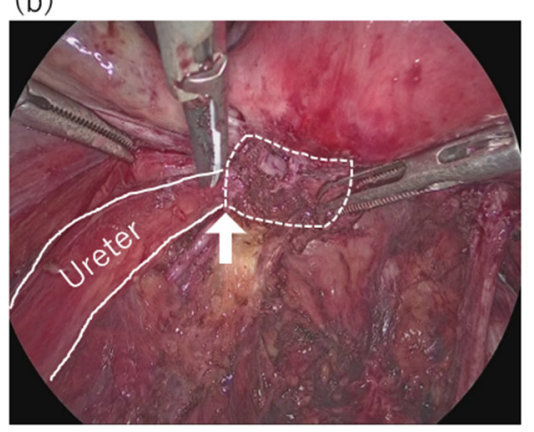

(c)

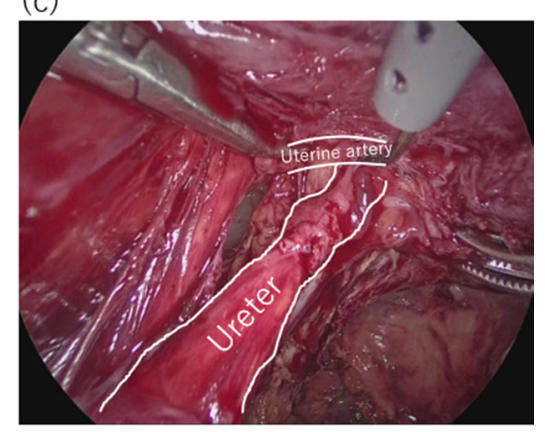

Figure 2. (a) The rectum adhered to the posterior wall of the uterus, and the pouch of Douglas was completely closed. (b) The ureter was entrapped in the DE around the left sacrouterine ligament. (c) When the ureter was detached from the DE, the ureter was completely opened. 
(a)

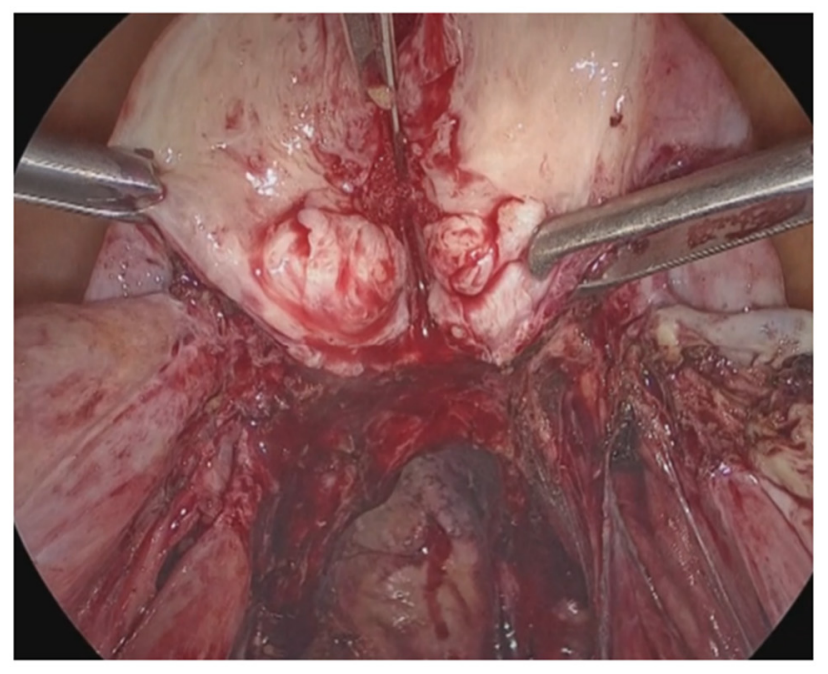

(b)

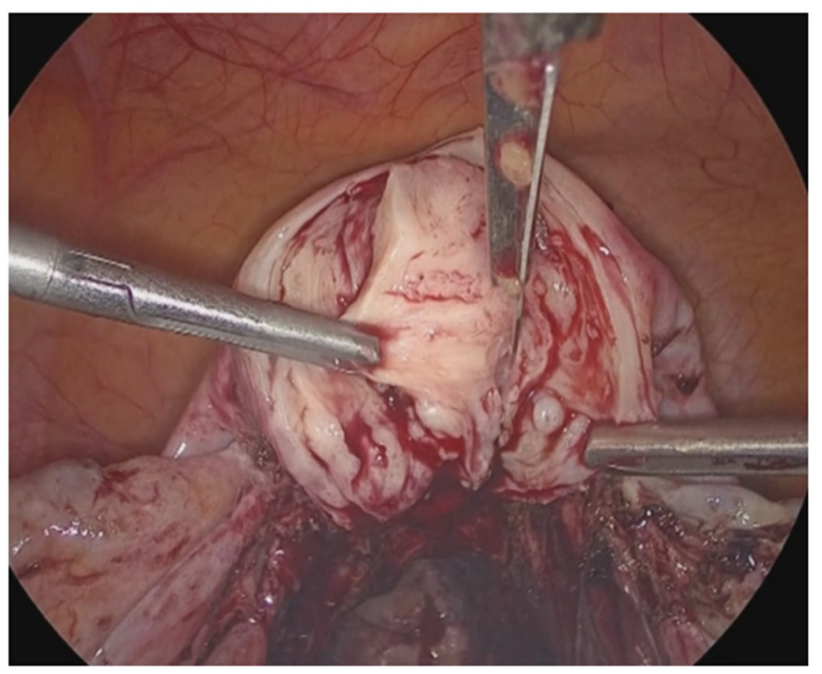

Figure 3. The laparoscopic adenomyomectomy procedure. (a) The uterus is longitudinally incised with the scalpel to access the adenomyotic tissue. (b) The nucleation is resected in a wide wedge shape with the scalpel in the posterior uterine wall.

Third, laparoscopic real-time elastography (ARIETTA 850; Hitachi, Ltd., Tokyo, Japan) was used to detect residual adenomyosis after initial enucleation. A posterior 1-2 cm transverse colpotomy was performed laparoscopically, precisely in the midline of the posterior fornix, which was demarcated using a Vagi-Pipe ${ }^{\circledR}$ (Hakko Medical, Nagano, Japan). A laparoscopic ultrasound probe was inserted through the colpotomy incision. Residual adenomyosis would be displayed in blue on real-time elastography because the tissue is harder than the surrounding myometrium, which is displayed in green, and the endometrium, which is displayed in red. The ultrasound probe was attached to the uterine wound after excision of the adenomyosis to check for residual lesions. Residual adenomyosis is appropriately excised with scissor forceps (Figure 4a). No residual adenomyosis was found in the uterine wound (Figure 4 b).

(a)

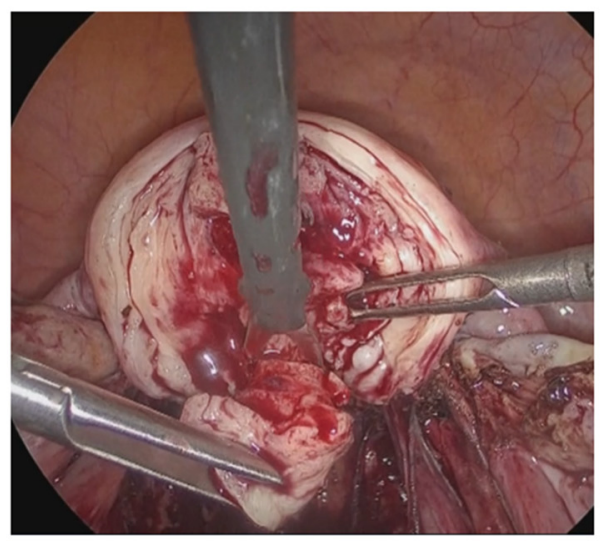

(b)

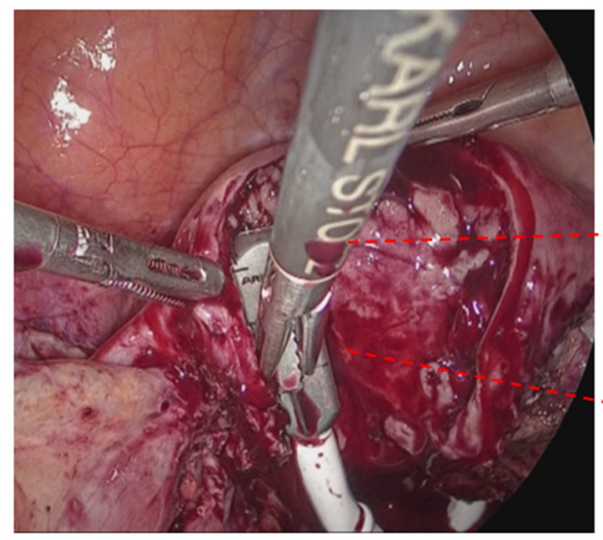

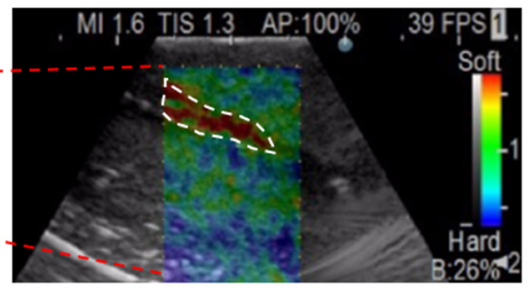

Figure 4. (a) Real-time elastography confirmed residual lesions, which were excised using scissor forceps. (b) The left side of the posterior wall of the uterus is shown in green, confirming that no residual lesions are noted. The red area indicates the endometrium.

The resected specimen was removed through a colpotomy incision into the vagina. The uterine wounds were repaired in multiple layers using barbed sutures (0 Stratafix Symmetric PDS Plus; Ethicon Endo-Surgery, Tokyo, Japan). After the myometrium was reapproximated and hemostasis was achieved, the serosal layer was closed using a synthetic absorbable suture (1-0 Vicry ${ }^{\circledR}$; Ethicon Endo-Surgery, Tokyo, Japan) with a CT-1 
needle. The suture layer was covered with a hemostatic agent (ARISTATMAH; Medafor, Minneapolis, MN, USA) and an anti-adhesion sheet (INTERCEED ${ }^{\circledR}$; Johnson \& Johnson, New Brunswick, NJ, USA). The operative time was $147 \mathrm{~min}$, with minimal bleeding and without intraoperative complications. The patient was discharged on the third postoperative day. Histopathological examination revealed that the endometrial glands and intrinsic stroma were intervening within the myometrium.

An eight-week postoperative transvaginal ultrasound revealed that the thickness of the posterior uterine wall muscle layer had decreased from 28 to $22.7 \mathrm{~mm}$, with a reduction rate of $21.4 \%$ (Figure $5 \mathrm{a}$ ). Furthermore, transvaginal Doppler ultrasound demonstrated good blood flow recovery (Figure $5 b$ ). Additionally, the left hydronephrosis had resolved, and the stent was scheduled to be removed 6 months after surgery. Postoperative magnetic resonance imaging (MRI) 16 weeks after the surgery revealed complete uterine reconstruction (Figure 5c). She no longer experienced dysmenorrhea four months after surgery. Preoperatively, the visual analog scale score for the severity of dysmenorrhea was 83 [ranging from 0 (no pain) to 100 (extremely severe pain)], whereas the postoperative score was 16.

(a)

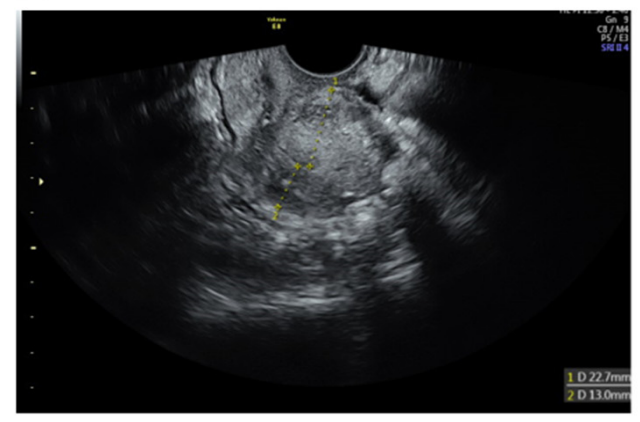

(b)

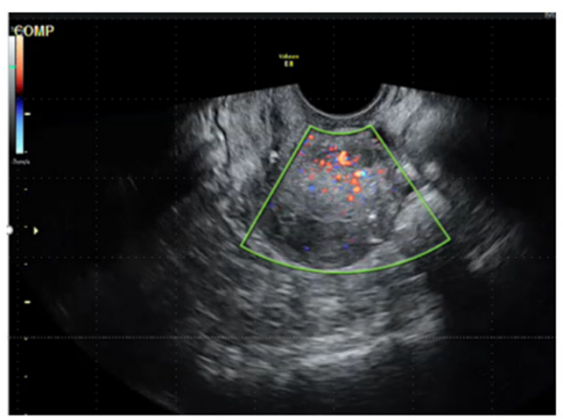

(c)

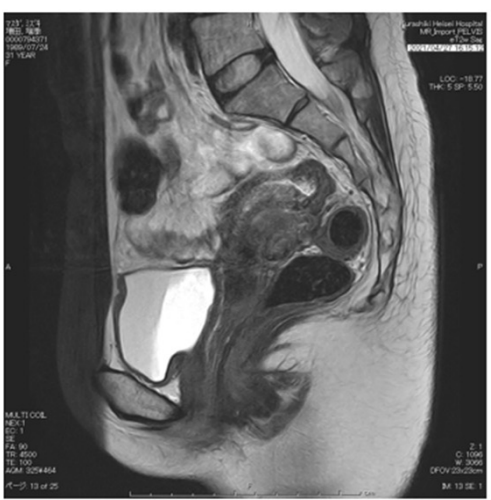

Figure 5. (a) Two months after surgery, a transvaginal ultrasound shows that the thickness of the posterior wall of the uterus had decreased from 28 to $22.7 \mathrm{~mm}$. (b) Transvaginal Doppler ultrasound showing good recovery of blood flow in the repaired muscle layer. (c) Sagittal T2-weighted postoperative pelvic magnetic resonance imaging. The image shows normal thickness.

\section{Discussion}

In this study, intraoperative real-time elastography and resection with scalpels were useful for subtype II (extrinsic) adenomyosis.

There are two types of adenomyosis: diffuse and focal. In diffuse adenomyosis, the boundary between the adenomyosis and the normal muscle layer is indistinguishable [20]. Therefore, the definitive cure is hysterectomy, which is frequently the treatment of choice for women with significant symptoms [21,22]. An alternative conservative treatment is adenomyomectomy via laparotomy or laparoscopy $[23,24]$. Grimbizis reviewed studies on adenomyomectomy as a uterus-sparing surgical treatment option for adenomyosis and concluded that this procedure was feasible and efficient [25]. A recent review included studies with short-term follow-up [26] and concluded that more than three-fourths of patients experienced symptom relief after conservative surgery [26]. Conversely, although adenomyomectomy is a viable treatment option, the majority of these surgeries have a high recurrence rate and can lead to uterine rupture during subsequent pregnancies. Because the boundary is often obscured, resection of the lesion may be insufficient, or too much of the normal myometrium may be removed [22,23]. If a uterine rupture occurs, there is a risk of death for both the mother and child. Osada et al. searched the main medical literature and found that a total of 397 post-procedural pregnancies were reported, with $337(84.89 \%)$ resulting in live births and $23(6.8 \%)$ instances of the ruptured uterus [27]. In contrast, it may raise the possibility that the benefits of conservative surgery overcome the potential 
complications. Additionally, Kwak et al. described that pregnant women who underwent adenomyomectomy could achieve safe perinatal outcomes under close monitoring of preterm labor and surveillance of catastrophic pregnancy-related complications [28].

Since the appearance of the power instrument in the 1980s, laparoscopic surgery has become more widely used and has become a necessary tool for incision and tissue collection, while shortening operation times. However, laparoscopic surgery also causes hardening and discoloration of the surface of the incision due to thermal degeneration, and the boundary between abnormal and normal tissues remains unclear. The use of power instruments is associated with most cases of uterine rupture, and a causal relationship has been suspected [29]. We recently reported a case of subtype I adenomyosis treated using laparoscopic, conservative excision with intraoperative real-time elastography. After resection of the adenomyosis, the lesion was visualized using elastography, and the boundary between the adenomyosis and the normal myometrium was carefully and tactilely resected with scalpel and scissor forceps without using a power instrument, such as harmonic scalpels, such that only the adenomyosis lesion was being completely resected [18]. In this case, we used cold scalpels instead of a power instrument because prior experience demonstrated that electrosurgery induced thermal denaturation and prevented distinguishing between the adenomyosis and the normal endometrium.

We previously proposed that myometrial blood flow should be assessed to evaluate healing after adenomyomectomy [18] because myometrial defects and subsequent infection or hematoma formation within the myometrium during postoperative wound healing can cause spontaneous uterine rupture [29,30]. In this case, postoperative transvaginal ultrasonography was used to confirm abundant intramuscular blood flow and the absence of hematoma. In addition, postoperative MRI was showed to reconstruct the normal myometrial thickness.

Moreover, efficient, safe and feasible surgical methods for adenomyomectomy are still discussed as to effectively preventing rupture in the long run for conservative surgery in adenomyosis treatment because adenomyomectomy is associated with risk of uterine rupture during pregnancy [23]. Since the first description of traditional adenomyomectomy by Hyam [31] in 1952, various adenomyomectomy protocols have been improved clinically [32-34]. However, even with the surgical methods that are still being improved, uterine rupture is still recognized [35,36]. This method including the previous report [18] is not evaluated the prognosis of perinatal outcomes. Therefore, the perinatal outcomes should be further assessed in long term, large-sample-size, and prospective clinical studies.

\section{Conclusions}

There is no consensus on adenomyomectomy because the boundary between the adenomyosis and the normal myometrium was unclear. In this study, we experienced a case of subtype 2 adenomyosis that was initially resected using scalpel and scissor forceps and then completely resected with monitoring of the residual adenomyosis using intraoperative real-time elastography. We further need to increase the number of cases and conduct prospective studies of the perinatal prognosis; however, we believe that this surgical technique will provide new evidence.

Author Contributions: Conceptualization, Y.O., K.O. and I.O.; Methodology, R.S. and Y.M.; Data collection, R.S. and S.-I.S.; Writing-original draft preparation, Y.O. and K.O.; Writing-review and editing, T.T.; Supervision, T.M. and M.S. All authors have read and agreed to the published version of the manuscript.

Funding: The APC was funded by the Department of Gynecological Oncology, Kawasaki Medical School.

Institutional Review Board Statement: The study was conducted according to the guidelines of the Declaration of Helsinki. Ethical review and approval were waived for this report due to case report.

Informed Consent Statement: Written informed consent has been obtained from the patient to publish this paper. 
Data Availability Statement: The data that support the findings of this study are available from the corresponding author, K.O., upon reasonable request.

Conflicts of Interest: The authors declare no conflict of interest.

\section{References}

1. Tosti, C.; Pinzauti, S.; Santulli, P.; Chapron, C.; Petraglia, F. Pathogenetic Mechanisms of Deep Infiltrating Endometriosis. Reprod. Sci. 2015, 22, 1053-1059. [CrossRef] [PubMed]

2. Bird, C.C.; McElin, T.W.; Manalo-Estrella, P. The elusive adenomyosis of the uterus-revisited. Am. J. Obstet. Gynecol. 1972, 112, 583-593. [CrossRef]

3. $\quad$ Siegler, A.M.; Camilien, L. Adenomyosis. J. Reprod. Med. 1994, 39, 841-853.

4. Bergeron, C.; Amant, F.; Ferenczy, A. Pathology and physiopathology of adenomyosis. Best Pract. Res. Clin. Obstet. Gynaecol. 2006, 20, 511-521. [CrossRef]

5. Gordts, S.; Brosens, J.J.; Fusi, L.; Benagiano, G.; Brosens, I. Uterine adenomyosis: A need for uniform terminology and consensus classification. Reprod. Biomed. Online 2008, 17, 244-248. [CrossRef]

6. Canis, M.; Donnez, J.G.; Guzick, D.S.; Halme, J.K.; Rock, J.A.; Schenken, R.S.; Vernon, M.W. Revised american society for reproductive medicine classification of endometriosis: 1996. Fertil. Steril. 1997, 67, 817-821.

7. Keckstein, J.; Ulrich, U.; Possover, M.; Schweppe, K. ENZIAN-Klassifikation der tief infiltrierenden Endometriose. Zentralbl. Gynäkol. 2003, 125, 291.

8. Haas, D.; Wurm, P.; Shamiyeh, A.; Shebl, O.; Chvatal, R.; Oppelt, P. Efficacy of the revised Enzian classification: A retrospective analysis. Does the revised Enzian classification solve the problem of duplicate classification in rASRM and Enzian? Arch. Gynecol. Obstet. 2013, 287, 941-945. [CrossRef]

9. Haas, D.; Shebl, O.; Shamiyeh, A.; Oppelt, P. The rASRM score and the Enzian classification for endometriosis: Their strengths and weaknesses. Acta Obstet. Gynecol. Scand. 2013, 92, 3-7. [CrossRef]

10. Kishi, Y.; Suginami, H.; Kuramori, R.; Yabuta, M.; Suginami, R.; Taniguchi, F. Four subtypes of adenomyosis assessed by magnetic resonance imaging and their specification. Am. J. Obstet. Gynecol. 2012, 207, 114.e1-114.e7. [CrossRef] [PubMed]

11. Kishi, Y.; Shimada, K.; Fujii, T.; Uchiyama, T.; Yoshimoto, C.; Konishi, N.; Ohbayashi, C.; Kobayashi, H. Phenotypic characterization of adenomyosis occurring at the inner and outer myometrium. PLoS ONE 2017, 12, e0189522. [CrossRef] [PubMed]

12. Brosens, I.; Gordts, S.; Habiba, M.; Benagiano, G. Uterine Cystic Adenomyosis: A Disease of Younger Women. J. Pediatric Adolesc. Gynecol. 2015, 28, 420-426. [CrossRef]

13. Abu Hashim, H.; Elaraby, S.; Fouda, A.A.; Rakhawy, M.E. The prevalence of adenomyosis in an infertile population: A crosssectional study. Reprod. Biomed. Online 2020, 40, 842-850. [CrossRef]

14. Cheng, M.-H.; Wang, P.-H. Uterine myoma: A condition amendable to medical therapy? Expert Opin. Emerg. Drugs 2008, 13, 119-133. [CrossRef] [PubMed]

15. Fedele, L.; Bianchi, S.; Zanotti, F.; Marchini, M.; Candiani, G.B. Surgery: Fertility after conservative surgery for adenomyomas. Hum. Reprod. 1993, 8, 1708-1710. [CrossRef]

16. Maheshwari, A.; Gurunath, S.; Fatima, F.; Bhattacharya, S. Adenomyosis and subfertility: A systematic review of prevalence, diagnosis, treatment and fertility outcomes. Hum. Reprod. Update 2012, 18, 374-392. [CrossRef] [PubMed]

17. Louis, L.; Saso, S.; Chatterjee, J.; Barsoum, E.; Al-Samarrai, M. Adenomyosis and infertility. Reprod. Biomed. Online 2012, $24,586$. [CrossRef]

18. Ota, Y.; Ota, K.; Takahashi, T.; Suzuki, S.; Sano, R.; Shiota, M. New surgical technique of laparoscopic resection of adenomyosis under real-time intraoperative ultrasound elastography guidance: A case report. Heliyon 2020, 6, e04628. [CrossRef] [PubMed]

19. Agha, R.A.; Borrelli, M.R.; Farwana, R.; Koshy, K.; Fowler, A.J.; Orgill, D.P.; Zhu, H.; Alsawadi, A.; Noureldin, A.; Rao, A.; et al. The SCARE 2018 statement: Updating consensus Surgical CAse REport (SCARE) guidelines. Int. J. Surg. 2018, 60, 132-136. [CrossRef]

20. Van den Bosch, T.; de Bruijn, A.M.; de Leeuw, R.A.; Dueholm, M.; Exacoustos, C.; Valentin, L.; Bourne, T.; Timmerman, D.; Huirne, J.A.F. Sonographic classification and reporting system for diagnosing adenomyosis. Ultrasound Obstet. Gynecol. $2019,53,576-582$. [CrossRef]

21. Wang, P.-H.; Liu, W.-M.; Fuh, J.-L.; Cheng, M.-H.; Chao, H.-T. Comparison of surgery alone and combined surgical-medical treatment in the management of symptomatic uterine adenomyoma. Fertil. Steril. 2009, 92, 876-885. [CrossRef]

22. Levgur, M. Therapeutic options for adenomyosis: A review. Arch. Gynecol. Obstet. 2007, 276, 1-15. [CrossRef]

23. Wada, S.-I.; Kudo, M.; Minakami, H. Spontaneous uterine rupture of a twin pregnancy after a laparoscopic adenomyomectomy: A case report. J. Minim. Invasive Gynecol. 2006, 13, 166-168. [CrossRef]

24. Takeuchi, H.; Kitade, M.; Kikuchi, I.; Shimanuki, H.; Kumakiri, J.; Kitano, T.; Kinoshita, K. Laparoscopic adenomyomectomy and hysteroplasty: A novel method. J. Minim. Invasive Gynecol. 2006, 13, 150-154. [CrossRef]

25. Grimbizis, G.F.; Mikos, T.; Tarlatzis, B. Uterus-sparing operative treatment for adenomyosis. Fertil. Steril. 2014, 101, 472-487.e8. [CrossRef]

26. Younes, G.; Tulandi, T. Conservative Surgery for Adenomyosis and Results: A Systematic Review. J. Minim. Invasive Gynecol. 2018, 25, 265-276. [CrossRef]

27. Osada, H. Uterine adenomyosis and adenomyoma: The surgical approach. Fertil. Steril. 2018, 109, 406-417. [CrossRef] 
28. Kwack, J.-Y.; Lee, S.-J.; Kwon, Y.-S. Pregnancy and delivery outcomes in the women who have received adenomyomectomy: Performed by a single surgeon by a uniform surgical technique. Taiwan J. Obstet. Gynecol. 2021, 60, 99-102. [CrossRef]

29. Parker, W.H.; Einarsson, J.; Istre, O.; Dubuisson, J.-B. Risk Factors for Uterine Rupture after Laparoscopic Myomectomy. J. Minim. Invasive Gynecol. 2010, 17, 551-554. [CrossRef]

30. Pelosi, M.A., III. Spontaneous uterine rupture at thirty-three weeks subsequent to previous superficial laparoscopic myomectomy. Am. J. Obstet. Gynecol. 1997, 177, 1547-1549. [CrossRef]

31. Hyams, L.L. Adenomyosis; its conservative surgical treatment (hysteroplasty) in young women. N. Y. State J. Med. 1952, 52, 2778-2784.

32. Fujishita, A.; Masuzaki, H.; Khan, K.N.; Kitajima, M.; Ishimaru, T. Modified reduction surgery for adenomyosis. A preliminary report of the transverse H incision technique. Gynecol. Obstet. Investig. 2004, 57, 132-138. [CrossRef]

33. Nishida, M.; Takano, K.; Arai, Y.; Ozone, H.; Ichikawa, R. Conservative surgical management for diffuse uterine adenomyosis. Fertil. Steril. 2010, 94, 715-719. [CrossRef]

34. Osada, H.; Silber, S.; Kakinuma, T.; Nagaishi, M.; Kato, K.; Kato, O. Surgical procedure to conserve the uterus for future pregnancy in patients suffering from massive adenomyosis. Reprod. Biomed. Online 2011, 22, 94-99. [CrossRef]

35. Saremi, A.; Bahrami, H.; Salehian, P.; Hakak, N.; Pooladi, A. Treatment of adenomyomectomy in women with severe uterine adenomyosis using a novel technique. Reprod. Biomed. Online 2014, 28, 753-760. [CrossRef]

36. Makino, S.; Takeda, S.; Kondoh, E.; Kawai, K.; Takeda, J.; Matsubara, S.; Itakura, A.; Sago, H.; Tanigaki, S.; Tanaka, M. National survey of uterine rupture in Japan: Annual report of Perinatology Committee, Japan Society of Obstetrics and Gynecology, 2018. J. Obstet. Gynaecol. Res. 2019, 45, 763-765. [CrossRef] 